\title{
EDITORIAL Carta de Porto Alegre - Rio Grande do Sul ESPECIAL SPECIAL
}

EDITORIAL

Os epidemiologistas brasileiros reunidos no VII Congresso Brasileiro de Epidemiologia, em Porto Alegre, no período de 20 a 24 de setembro de 2008, vêm a público reafirmar a grande relevância das comunicações e debates ocorridos neste importante evento, organizado pela Associação Brasileira de Pós-Graduação em Saúde Coletiva - ABRASCO.

Em primeiro lugar, impõe-se destacar o elevado grau de amadurecimento alcançado pela epidemiologia no Brasil ao demonstrar presença segura e conseqüente no estudo de todas as questões relevantes e atuais que demarcam a Saúde no país, seja do ponto de vista analítico e metodológico, bem como da perspectiva da formulação de propostas de atuação. Isto se reforça, com o acolhimento e realização conjunta do XVIII Congresso Mundial de Epidemiologia.

Ao lado dos grandes avanços observados na sociedade brasileira no controle e erradicação de doenças, os desafios se multiplicam. Compreendem os velhos e conhecidos problemas ao lado de outros novos que invadem o cotidiano da população brasileira, como o são o alcoolismo, o tabagismo, as outras drogas, a violência, entre outros.

Em harmonia com o tema central do Congresso "Epidemiologia na construção da saúde para todos: métodos para um mundo em transformação", ficou evidente para os congressistas que a efetividade de sua atuação só se concretiza na medida da urgente regulamentação da EC-29 que define os recursos financeiros necessários para a sustentabilidade do nosso sistema de saúde. Ao lado disso, torna-se impositiva a provisão de condições dignas e justas de trabalho dos profissionais de saúde, cujos empenho e dedicação não têm sido devidamente valorizados e reconhecidos, especialmente, quando comparados a outros setores públicos.

O debate trouxe a tona um conjunto relevante de evidências que reafirmam o papel dos determinantes sociais na iníqua distribuição da saúde populacional, o que implica a necessidade do estabelecimento de políticas públicas intersetoriais e de estratégias de avaliação contínua dessas intervenções e seus efeitos sobre as desigualdades em saúde.

Refletindo sobre a atual conjuntura mundial, manifestam sua indignação frente aos recentes desdobramentos da economia globalizada que se transformou em uma ciranda financeira, utilizando inapropriadamente vultosos recursos públicos. Estes que, certamente, são necessários para as áreas sociais de todos os países, seriam suficientes para atenuar o sofrimento vivenciado, na área da saúde, pelas sociedades desprovidas de recursos, como é o caso, por exemplo, da maioria da população africana.

Por fim, baseados na reunião de Ministros da Saúde da Comunidade dos Países de Língua Portuguesa realizada por ocasião dos Congressos, os epidemiologistas reconhecem que o enfrentamento dos desafios postos pelo processo saúde-doença implica a organização de um novo pacto. Este deve ser demarcado pela solidariedade entre povos deste e de outros continentes e pelo trabalho cooperativo internacional, como base de sustentação e de efetivação, para que se possa dar conseqüência ao lema de que a saúde, menos do que gasto, é condição essencial para o digno e pleno desenvolvimento das sociedades.

Porto Alegre, 24 de setembro de 2008.

Comissão de Epidemiologia da Abrasco 